\title{
Mesitylgold(I) and silver(I) perfluorocarboxylates as precursors of supramolecular Au/Ag systems.
}

Eduardo J. Fernández ${ }^{\S}$, Antonio Laguna**, José M. López-de-Luzuriaga ${ }^{\S}$, M. Montiel ${ }^{\S}$, M. Elena Olmos $^{\S}$, Javier Pérez $z^{\S}$ and Raquel C. Puelles ${ }^{\S}$

Supplementary Material 
Figure S1. Crystal structure of complex 3 viewed down the crystallographic $z$ axis. Fluorine and hydrogen atoms have been omitted for clarity reasons.

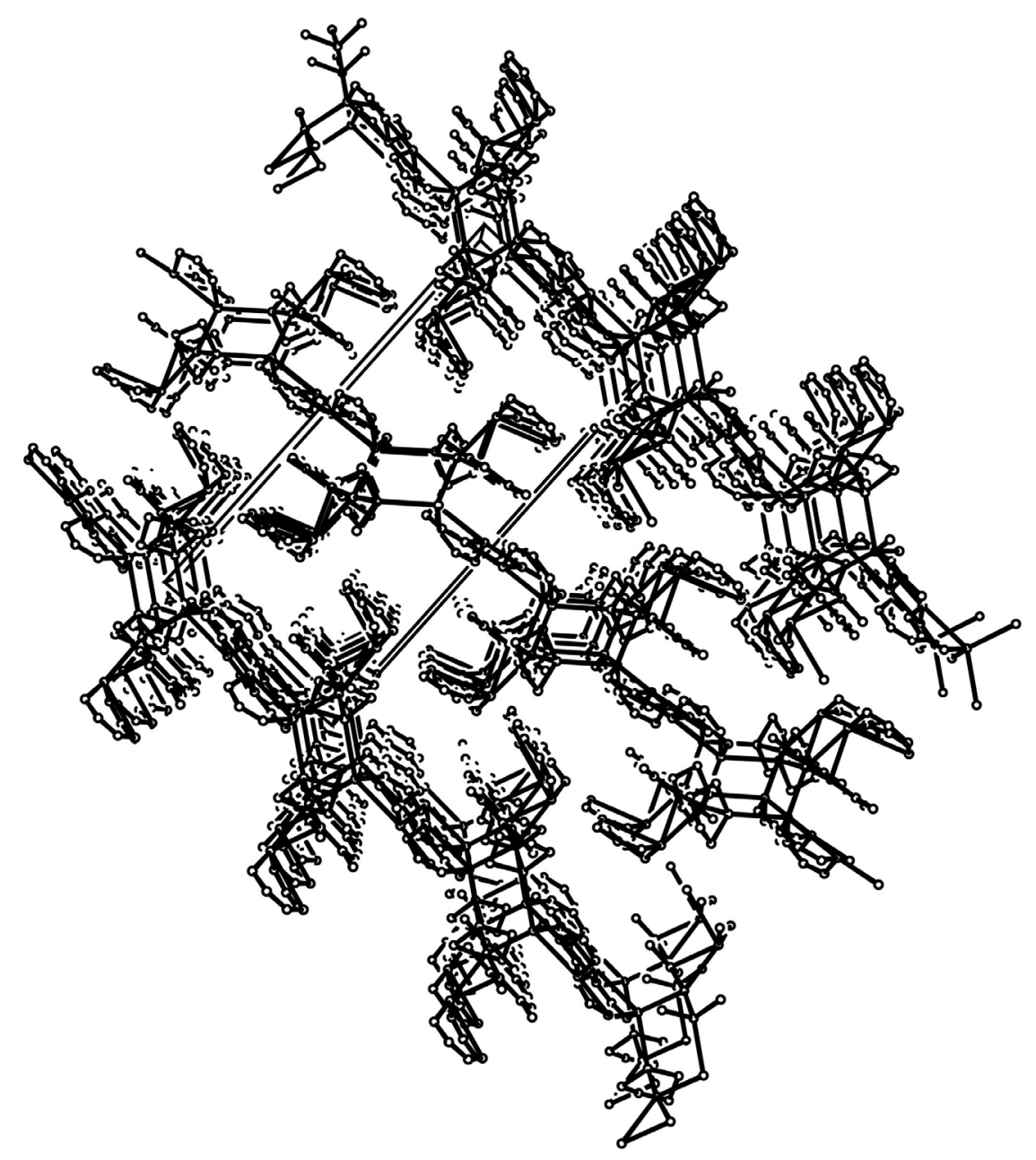


Figure S2. Crystal structure of complex 4 viewed down the crystallographic $x$ axis. Fluorine and hydrogen atoms have been omitted for clarity reasons.

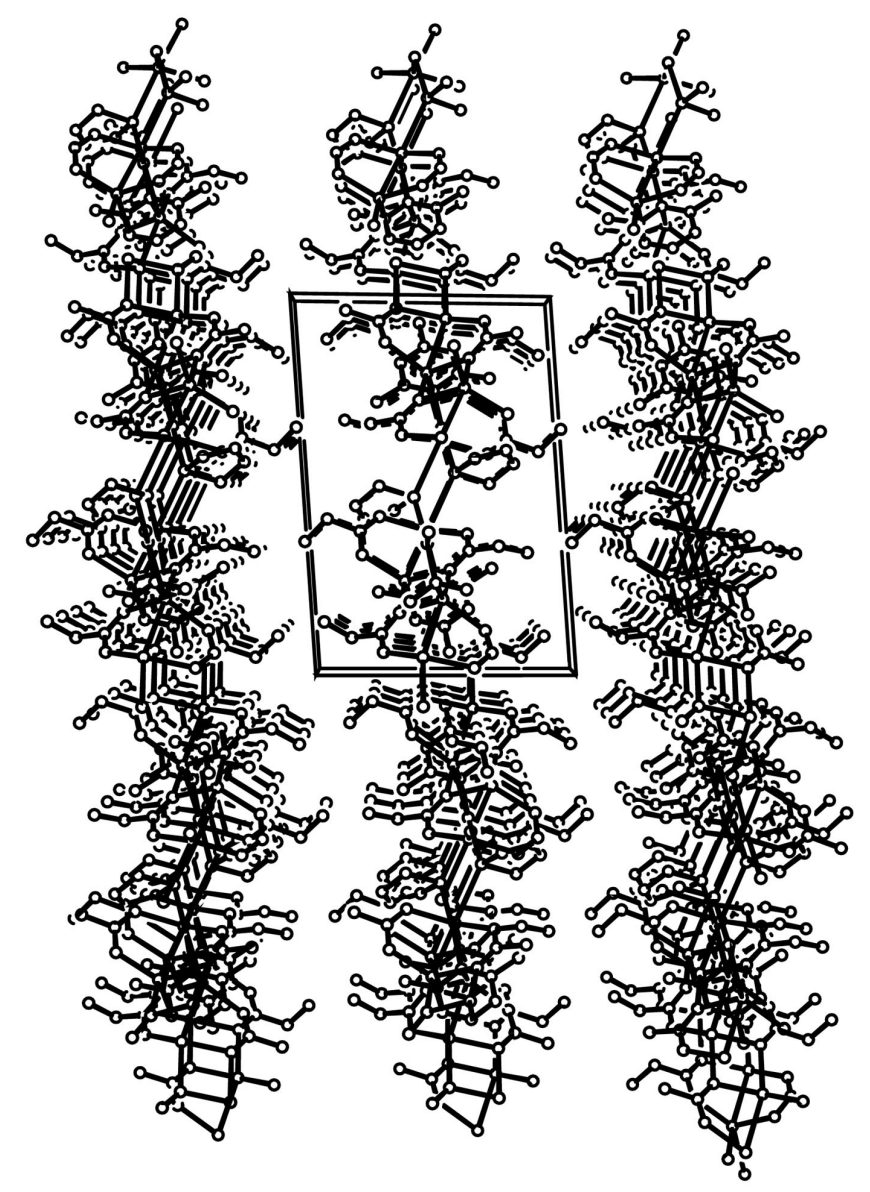


Figure S3. Crystal structure of complex 6 viewed down the crystallographic $y$ axis. Fluorine and hydrogen atoms have been omitted for clarity reasons.

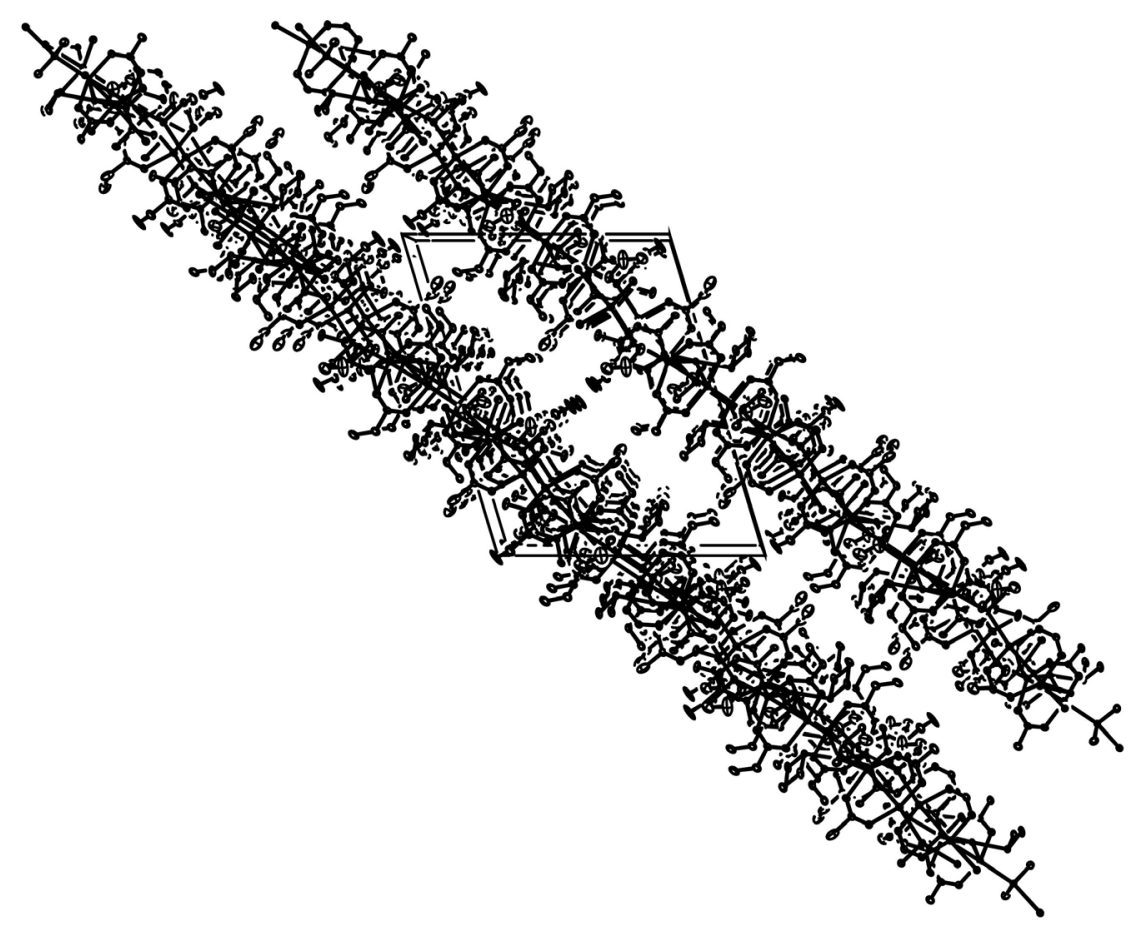


Figure S4. Crystal structure of complex 7 viewed down the crystallographic $y$ axis. Fluorine and hydrogen atoms have been omitted for clarity reasons.

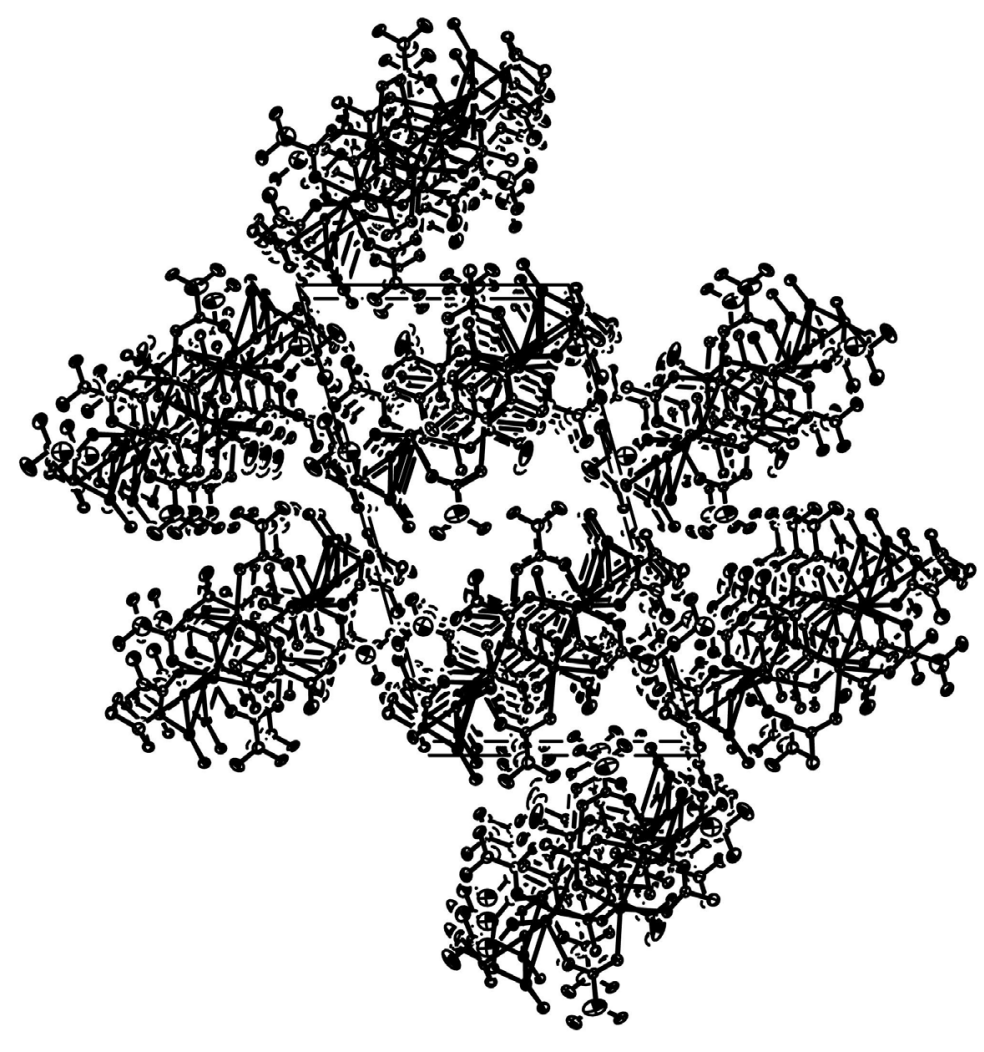

